\title{
Effect of coir fiber loading on mechanical and morphological properties of oil palm fibers reinforced polypropylene composites
}

\begin{abstract}
Hybrid composites were fabricated by compounding process with varying the relative weight fraction of oil palm empty fruit bunch (EFB) and coir fibers to assess the effect of hybridization of oil palm EFB with coir fibers in polypropylene (PP) matrix. The mechanical and morphological properties of oil palm/coir hybrid composites were carried out. Tensile and flexural properties of oil EFB-PP composites enhanced with hybridization of coir fibers except coir/oil palm EFB (25:75) hybrid composite, whereas highest impact properties at oil palm:coir fibers with 50:50 ratios. Results shown that hybrid composites with oil palm:coir fibers with 50:50 ratios display optimum mechanical properties. In this study, scanning electron microscopy (SEM) had been used to study morphology of tensile fractured surface of hybrid composites. Its clear from SEM micrograph that coir/EFB (50:50) hybrid composites display better tensile properties due to strong fiber/matrix bonding as compared with other formulations which lead to even and effective distribution of stress among fibers. The combination of oil palm EFB/coir fibers with PP matrix produced hybrid biocomposites material can be used to produce components such as rear mirrors' holder and window levers, fan blades, mallet, or gavel.
\end{abstract}

Keyword: Mechanical and morphological properties; Oil palm EFB/coir fibers; Hybrid composites; Polypropylene composites 